\title{
Study on the Prevalence of Endoparasites in Small Holder Dairy Farm in and around Harar Town, Oromia Regional State, Eastern Ethiopia
}

\author{
Lamessa Keno ${ }^{1}$, Birhanu Abera ${ }^{2 *}$, Diriba Lemma ${ }^{2}$, Eyob Eticha ${ }^{2}$ and Guluma Assefa ${ }^{1}$ \\ ${ }^{1}$ East Shoa Zone Livestock and Fishery Resource Office, Adama, Ethiopia
}

${ }^{2}$ Asella Regional Veterinary Laboratory, PO Box 212, Asella, Ethiopia

\begin{abstract}
A cross- sectional study of prevalence of Gastro-intestinal helminthiasis of small holder dairy cows was carried out from December 2007 to April 2008 with an attempt to determine the prevalence in Harar town and its surrounding, Eastern Ethiopia. Amongst the 287 coprological analysis or quantitative faecal analysis on dairy cows were performed with an overall prevalence rate $139(48.4 \%)$ by using coprological examination. Coprological examination (Direct, Floatation, sedimentation and Mc Master Techniques) were the methods followed to study the prevalence of $\mathrm{Gl}$ - parasitic infestation. An overall GI-parasitic infestation of $48.4 \%$ was found in this study. The result also revealed that nematodes Strongyles $(38.4 \%)$ and Trichuris $(8.4 \%)$, paraphistomum $(13.9 \%)$ and Coccidia $(10.5 \%)$ in that order. The helminth eggs present were identified in general terms as strongyloid eggs, since relevant nematode genera produce eggs that are similar in appearance and cannot be discriminated easily, except for eggs of Nematodirus, Strongyloides and Trichuris. In view of the prevalence of hazardous parasitic gastro intestinal parasites with a potential of entailing serious direct and indirect losses, and accompanying in these small holder dairy cows deserve attention and pertinent action to see they are controlled because high economic importance deserving due attention in helminth control programs in the study area.
\end{abstract}

Keywords: Small holder; Dairy cow; Prevalence; Helminthiasis; Harar; Eastern Ethiopia

\section{Introduction}

The growing demand for the meat and milk in developing world, changing function of livestock and changing consumers perspectives are the major driving forces in the global livestock sector during the next two decades [1].

The Ethiopian dairy system can be paraphrased by the statement that "though there is huge livestock population with high potential for milk and dairy production and there are ever more people tend to drink milk and consume more dairy products yet milk production is still too low in the country to satisfy the needs which is hampered by bucketful of paradoxes, hopes and heartbreaks". The Ethiopian livestock population is the highest in African continent and there has been efforts exerted to develop the sector, but the outcomes are insignificant (the paradox) [2].

Helminth infection, especially subclinical gastrointestinal nematode infections are among the major health problems limiting the productivity in dairy animals [3]. Economic losses are caused by gastrointestinal parasites in a variety of ways. The losses can be through lowered fertility, reduced work capacity, involuntary culling, a reduction in food intake and reduced weight gain, lower milk production, treatment costs and mortality in heavily parasitized animals [4]

Infectious diseases especially gastrointestinal parasites and exoparasites are considered as the major diseases of cattle in the study area. Helminth parasite infections in cattle are of the major importance in many agro ecological zones and are a primary factor in the reduction of productivity. This is further aggravated in small holder dairy farmers due to the limited availability of land and feed resources. Year round utilization of communal grazing and watering places shared livestock kept by smallholder are a major source of infection. The prevention and control of helminth parasites is not based on disease epidemiology rather is targeted at sick individual [5].

Gastrointestinal parasite infection is one of the major causes of wastage and decreased productivity exerting their effect through mortality, morbidity, decreased growth rate, weight loss in young growing calves and late maturity of slaughter stock, reduced milk and meat production and working capacity of the animal mainly in developing countries [6]. These effects largely relates to specific damage caused by the parasites including villous atrophy at the site of gastrointestinal nematode attachment and liver trauma resulting from the presence of migratory liver fluke [7]. Indirect effects have also been described, including altered feed intake, digest flow rate, nutrient absorption and liver metabolic activity, endocrine status and immunological response [8].

A number of helminths species are known to infect cattle worldwide. The most important ones include nema-todes like Strongyle species (Haemonchus, Ostartagia, Trichostrongylus, Cooperia) and trematodes of economic importance Fasciola species (Fasciola hepatica and Fasciola gigantica) and Paraphistomum species (Paraphistomum cervei), while cestodes like Monezia species (Monezia benideni and Monezia expanza) could also be important constraints in animal production [9]

Small holders or pastoralist may not easily detect the effects of internal parasites on their animals, because of generally sub-clinical or chronic nature of the nematode infections $[10,11]$. Thus the subclinical parasite infections are responsible for significant economic loss, because

*Corresponding author: Birhanu Abera, Asella Regional Veterinary Laboratory, PO Box 212, Asella, Ethiopia, Tel: +0913333944; E-mail: birhanuabera27@yahoo.com

Received December 13, 2016; Accepted Janauray 05, 2017; Published Janauray 07,2017

Citation: Keno L, Abera B, Lemma D, Eticha E, Assefa G (2017) Study on the Prevalence of Endoparasites in Small Holder Dairy Farm in and around Harar Town, Oromia Regional State, Eastern Ethiopia. J Vet Sci Technol 8: 411. doi: 10.4172/2157-7579.1000411

Copyright: $\odot 2017$ Keno L, et al. This is an open-access article distributed under the terms of the Creative Commons Attribution License, which permits unrestricted use, distribution, and reproduction in any medium, provided the original author and source are credited. 
once clinical disease is noticed in a group of animal productivity has already occurred $[12,13]$

Parasitic gastro enteritis is very important causes of production losses including the direct effect of severe clinical signs such as anemia, associated edema, diarrhea and anorexia [14]. The investigation and identification of the prevalence and to know the burden of gastrointestinal parasites are very important to give veterinary care and to get expected product from dairy cattle. Therefore the objective of this study was to know prevalence of endoparasites and to identify species of parasites in the area based on coprological examination.

\section{Study Materials and Methods}

\section{Description of the study area}

A cross sectional study was carried out from December 2007 to April 2008 in Harar town and its surrounding (capital of eastern Hararghe region). Harar is situated $526 \mathrm{~km}$ east of Addis Ababa altitudes ranges from 1300 to $2200 \mathrm{~m}$ and total coverage of the area is $343.2 \mathrm{~km}^{2}$. Mean annual temperate and rainfall ranger between $19.2^{\circ} \mathrm{C}-20^{\circ} \mathrm{C}$ and $67.1-$ $804.7 \mathrm{~mm}$ respectively according to Harar agricultural office report. This area has a mid-tropical weather (woyna dega) and highland temperate climate (Dega) accounting respectively $76 \%$ and $24 \%$ of the climate. Agriculture is the main occupation of the population of the area. The agricultural activities are mainly mixed type with cattle, sheep, goats, rearing and crop production undertaken side by side. According to the information obtained from the veterinary section of Harar agricultural office report 1998/1999 [15], the total livestock population of this region was estimated at 36,098 cattle, 19,973 goats, 6,067 sheep, 6,487 equines and 34,525 poultry. The major annual crops include sorghum, wheat, maize and chat. The major types of soil in the area supporting the crops and the flora of the area are chromic cambisols 7\%, chromic luvisols $48 \%$, chromic vertisols $1 \%$, eutric nitosols $3 \%$ and vertic luvisols $41 \%$ type of soils.

\section{Study animals}

The study was conducted on small holder dairy farm in and around Harar town on 287 dairy cattle ( 253 female and 34 male). All the cattle found in each farms during the study period were subjects of the study.

\section{Study design}

A cross sectional survey was made on small holder dairy farm animals during the study period to investigate the prevalence of endoparasites through examination. Regular visits were made to the area for faecal sample collection. After a through collection of faecal sample and the sample was undertaken some examination.

\section{Coprological examination}

In field faecal samples were collected from study animals, directly from rectum and was transported to laboratory and examined. Three laboratory techniques were employed: Faecal samples were directly taken from the rectum and transported to laboratory for examination through direct smear, floatation, sedimentation and McMaster techniques.

Direct smear: A few drops of water plus an equivalent amount of faecal are mixed on a microscopic slide. Tilting the slide then allows the lighter eggs to flow away from the heavier debris, a coverslip is placed on the fluid and the preparation is then examined microscopically. It is possible to detect most eggs or larvae by this method, but due to the small amount of faeces used it may only detect relatively heavy infection [16].

Floatation method: The basis of any floatation method is that when worm eggs are suspended in a liquid with a specific gravity higher than that of the eggs, the latter will float up to the surface. Nematode and cestode eggs float in a liquid with a specific gravity of between 1.1 and 1.2, trematode eggs, which are much heavier, require a specific gravity of 1.3 to 1.35 . The floatation solution used for nematode and cestode ova are mainly based on $\mathrm{Nacl}$ or sometimes $\mathrm{MgSO}_{4}$. A saturated solution of these is prepared and stored for a few days and the specific gravity checked prior to usage.

Sedimentation method: From collected samples for each case 3 gms of faeces was measured and put in to a mortar. Then $42 \mathrm{ml}$ of $\mathrm{ZnSO}_{4}$ (zinc sulfate) solution as floating medium was added and crusher thoroughly with a pistle. The suspension then allowed passing through a mesh sieve in to a beaker and the one left was discarded. After gentle shaking, the suspension was poured in to conical centrifuge tube and centrifuged at $1500 \mathrm{rpm}$ for 3 minutes. After decanting the supernatant, the sediment was agitated till thick homogeneous fluid is obtained at the bottom of the tube and then filled equal amount of water to previous level. The content of the tube was mixed thoroughly with thumb over the open end of the tube. And then using a pasture pipette a $0.15 \mathrm{ml}$ fluid is taken from the suspension and placed on a microscope slide covered with cover slip. Then examined under low power objective [11].

McMaster method: This quantitative technique is used where it is desirable to count the number of eggs or larvae per gram of faeces. An abbreviated version of this techniques is to homogenize the $3 \mathrm{gm}$ of faeces in $42 \mathrm{ml}$ of salt solution, sieve, and pipette the filtrate directly in to the mc master slide. Finally number of eggs observed was registered and the total egg from two chamber and then multiply by 50 to get the total number of eggs per gram of faeces [16].

\section{Data Management and Analysis}

The data collected from the study area were coded and analyzed by using SPSS version 20 . The prevalence was calculated by dividing the number of animals harboring a given parasite by the total number of animals examined. Percentage to measure the prevalence of helminth and chi-square and t-test to measure association between prevalence of the helminth and the breeds, age, sex, lactation condition and body conditions of animals were employed. Variation of prevalence among or between age group, sex group and techniques was analyzed by chisquare $\left(\mathrm{X}^{2}\right)$ test. Confidence interval was held at $95 \%$ and $\mathrm{p}<0.05$ was set for significance level.

\section{Results}

Out of 287 dairy cattle examined in smallholder farms during the study period, using faecal sample qualitative examination, 139 (48.4\%) were detected to positive for internal parasites. Hence, the prevalence of internal parasites among age, sex and techniques of small holder dairy cows in and around Harar town shown in Tables 1-5 respectively. There were no statistically significant differences $(p>0.05)$ in infection rates between female and male, young and adult. Both sexes and age groups are equally susceptible and exposed to the parasite.

\section{Discussion}

During the study period in the study area, nine farms had been visited. The managemental supplementation given to the animal to the 
Citation: Keno L, Abera B, Lemma D, Eticha E, Assefa G (2017) Study on the Prevalence of Endoparasites in Small Holder Dairy Farm in and around Harar Town, Oromia Regional State, Eastern Ethiopia. J Vet Sci Technol 8: 411. doi: 10.4172/2157-7579.1000411

Page 3 of 5

\begin{tabular}{|c|c|c|}
\hline Number of farms & Address & Number of animals examined \\
\hline 1 & Kebele 13 & 30 \\
\hline 2 & Kebele 16 & 60 \\
\hline 3 & Kebele 16 & 30 \\
\hline 4 & Aretagna & 23 \\
\hline 5 & Amaressa & 31 \\
\hline 6 & Amaressa & 30 \\
\hline 7 & Kebele 17 & 24 \\
\hline 8 & Kebele 18 & 14 \\
\hline 9 & Abirabata & 45 \\
\hline & Total & 287 \\
\hline
\end{tabular}

Table 1A: Indicates the number of animal examined, address and number of farms.

\begin{tabular}{|c|c|c|c|}
\hline Age & Total examined & No. of positive & Prevalence (\%) \\
\hline$<2$ & 1 & 0 & 0 \\
$3 \leq 4$ & 19 & 2 & 10.5 \\
$>4$ & 267 & 41 & 15.4 \\
\hline Total & $\mathbf{2 8 7}$ & $\mathbf{4 3}$ & $\mathbf{1 5}$ \\
\hline Sex & & & \\
\hline F & 253 & 124 & 15.4 \\
M & 34 & 15 & 11.8 \\
\hline Total & $\mathbf{2 8 7}$ & $\mathbf{1 3 9}$ & $\mathbf{1 5}$ \\
\hline Techniques & & & \\
\hline Direct smear & 85 & 40 & 47.1 \\
Floatation & 106 & 59 & 55.7 \\
Sedimentation & 96 & 40 & 41.7 \\
\hline Total & $\mathbf{2 8 7}$ & $\mathbf{1 3 9}$ & $\mathbf{4 8 . 4}$ \\
\hline
\end{tabular}

Table 1B: The overall prevalence of helminthosis examined in the study area.

\begin{tabular}{|c|c|c|c|c|c|}
\hline Age & $\begin{array}{c}\text { Total } \\
\text { examined }\end{array}$ & $\begin{array}{c}\text { no. of } \\
\text { positive }\end{array}$ & Prevalence (\%) & $\mathbf{X}^{2}$ & p-value \\
\hline $\begin{array}{c}<2 \\
3 \leq 4 \\
>4\end{array}$ & $\begin{array}{c}1 \\
19 \\
267\end{array}$ & $\begin{array}{c}0 \\
2 \\
41\end{array}$ & $\begin{array}{c}0 \\
10.5 \\
15.4\end{array}$ & 0.5016 & 0.778 \\
\hline Total & 287 & 43 & 15 & & \\
\hline \multicolumn{6}{|l|}{ Sex } \\
\hline $\begin{array}{l}F \\
M\end{array}$ & $\begin{array}{c}253 \\
34\end{array}$ & $\begin{array}{c}39 \\
4\end{array}$ & $\begin{array}{l}15.4 \\
11.8\end{array}$ & 0.3135 & 0.576 \\
\hline Total & 287 & 43 & 15 & & \\
\hline \multicolumn{6}{|l|}{ Techniques } \\
\hline $\begin{array}{l}\text { Direct smear } \\
\text { Floatation } \\
\text { Sedimentation }\end{array}$ & $\begin{array}{c}\mathrm{t} 85 \\
106 \\
96\end{array}$ & $\begin{array}{c}6 \\
18 \\
0\end{array}$ & $\begin{array}{c}7.1 \\
17 \\
0\end{array}$ & & \\
\hline Total & 287 & 24 & 8.4 & & \\
\hline
\end{tabular}

Table 2: Prevalence of Strongyle eggs in small holder dairy cow by age, sex and techniques.

animal in the all farm is almost similar. Regarding to housing system, among the type of housing system, the all farms are loose type from opening type of housing system and closed type of housing system in which its ground surface was concrete. In relation to feeding system, concentrate, Roughages and feed residue like residues of wheat from Harar brewery always supplied to the all age groups. Besides the health aspects, mastitis is the most core point of diseases that commonly affect lactating animals. Such serious condition may be due to low milking management in the farms. Regarding noninfectious disease, bloat is commonly affect farms. The animals are dewormed twice annually.

Based on the result of this study livestock diseases and their consequences have severe impact on the small holder farmer's livelihood directly or indirectly. The direct cause of disease is mortality of animals and the indirect effects include low out put such as meat, milk and draft power. Animal diseases have also been indicated as public health hazard which is the same with the current study [17].

Endo parasite is a wide spread ruminants health problems and cause significant economic loss to the livestock in Ethiopia. Lemma et al. [18] have reported that water logged and poorly drained areas with acidic soils in the highlands are often endemic areas for parasites.

Cross sectional study showed that Strongyle, Coccidia, Trichuris and Paramphistomum are the most internal parasites commonly affect

\begin{tabular}{|c|c|c|c|c|c|}
\hline Age & $\begin{array}{c}\text { Total } \\
\text { examined }\end{array}$ & $\begin{array}{c}\text { no. of } \\
\text { positive }\end{array}$ & $\begin{array}{c}\text { Prevalence } \\
\text { (\%) }\end{array}$ & $\mathbf{X}^{2}$ & p-value \\
\hline$<2$ & 1 & 0 & 0 & 0.7279 & 0.695 \\
$3 \leq 4$ & 19 & 3 & 15.8 & & \\
\hline 4 & 267 & 27 & 10.1 & & \\
\hline Total & 287 & 30 & 10.5 & & \multirow{2}{*}{0.354} \\
\hline Sex & \multicolumn{7}{|l|}{} & & \\
\hline F & 253 & 28 & 11.1 & 0.8608 & \\
\hline M & 34 & 2 & 5.9 & & \\
\hline Total & 287 & 30 & 10.5 & & \\
\hline Techniques & \multicolumn{7}{|l|}{} & & & \\
\hline Direct smear & 85 & 6 & 7.1 & & \\
\hline Floatation & 106 & 18 & 17 & & \\
Sedimentation & 96 & 0 & 0 & & \\
\hline Total & 287 & 24 & 8.4 & & \\
\hline
\end{tabular}

Table 3: Prevalence of coccidian oocyst in small holder dairy cow by age, sex and techniques.

\begin{tabular}{|c|c|c|c|c|c|}
\hline Age & $\begin{array}{c}\text { Total } \\
\text { examined }\end{array}$ & $\begin{array}{l}\text { No. of } \\
\text { positive }\end{array}$ & $\begin{array}{c}\text { Prevalence } \\
\text { (\%) }\end{array}$ & $\mathbf{X}^{2}$ & $p$-value \\
\hline$<2$ & 1 & 0 & 0 & & \\
\hline $3 \leq 4$ & 19 & 0 & 0 & 1.9698 & 0.373 \\
\hline$>4$ & 267 & 24 & 9 & & \\
\hline Total & 287 & 24 & 8.4 & & \\
\hline \multicolumn{6}{|l|}{ Sex } \\
\hline $\mathrm{F}$ & 253 & 24 & 9.5 & 35347 & $0 \cap 0 \Omega$ \\
\hline M & 34 & 0 & 0 & 0.0041 & 0.000 \\
\hline Total & 287 & 24 & 8.4 & & \\
\hline \multicolumn{6}{|l|}{ Techniques } \\
\hline Direct smear & 85 & 6 & 7.1 & & \\
\hline Floatation & 106 & 18 & 17 & & \\
\hline Sedimentation & 96 & 0 & 0 & & \\
\hline Total & 287 & 24 & 8.4 & & \\
\hline
\end{tabular}

Table 4: Prevalence of Trichuris eggs in small holder dairy cows by age, sex and techniques.

\begin{tabular}{|c|c|c|c|c|c|}
\hline Age & $\begin{array}{c}\text { Total } \\
\text { examined }\end{array}$ & $\begin{array}{c}\text { No. of } \\
\text { positive }\end{array}$ & $\begin{array}{c}\text { Prevalence } \\
\text { (\%) }\end{array}$ & $\mathbf{X}^{2}$ & p-value \\
\hline$<2$ & 1 & 0 & 0 & & \\
$3 \leq 4$ & 19 & 4 & 21.1 & 1.0098 & 0.604 \\
$>4$ & 267 & 36 & 13.5 & & \\
\hline Total & 287 & 40 & 13.9 & & \\
\hline Sex & \multicolumn{7}{|l|}{} & \\
\hline F & 253 & 31 & 12.3 & \multirow{2}{*}{5.0510} & 0.025 \\
\hline M & 34 & 9 & 26.4 & & \\
\hline Total & 287 & 40 & 13.9 & & \\
\hline Techniques & \multicolumn{7}{|l|}{} & & & \\
\hline Direct smear & 85 & 2 & 2.4 & & \\
\hline Floatation & 106 & 0 & 0 & & \\
Sedimentation & 96 & 38 & 39.6 & & \\
\hline Total & 287 & 40 & 13.9 & & \\
\hline
\end{tabular}

Table 5: Prevalence of Paramphistomum eggs in small holder dairy cows by age sex and techniques. 
the animals. Irrespective of their prevalence Strongyle is the most prevalent parasites affect the animal in the study area while Trichuris is the least one. The prevalence rates of the above parasitic infection are $15 \%, 10.5 \%, 8.4 \%$ and $13.9 \%$ in Strongyle, Coccidia, Trichuris and Paramphistomum respectively.

The present study is conducted with the aim of identifying GIhelminth and their prevalence on dairy cows. Coprological examination was performed on 287 dairy cows and the overall prevalence of GIparasites was found to be $48.4 \%$ which comparable to the report on dairy cow by Derib [19] in Bahir-Dar and its surrounding which is $50 \%$. The higher prevalence was also reported by Etsehiwot [20] to be $82.8 \%$ in Holeta and its surroundings and by Zerfu [21] to be $81 \%$ in Assela and its surroundings. The prevalence difference in different study area could have resulted from difference in management system, topography, deworming practices, and climatic condition that favors the survival of infective stage of the parasite and intermediate hosts.

There was no statistically significant difference $(\mathrm{p}>0.05)$ in prevalence between females (15.4\%) and males (11.8\%). This shows that sex seems have no effect on the prevalence and both sexes are equally susceptible and exposed to the disease. In this study, no significant variation in prevalence of internal parasites in dairy cow of different age groups, calves percentage is zero, young's (10.5\%) and adults $(15.4 \%)$ were observed statistically $(p>0.05)$. This indicates that age groups do not matter for the presence or prevalence of internal parasites in dairy cows and hence both age groups are equally susceptible to the diseases as well.

According to the current study result which indicated the prevalent helminth egg with respect to their 139(48.4\%) were infested by internal parasites genera like Strongyle (15\%). Coccidia (10.5\%), Trichuris $(8.4 \%)$ and Paramphistomum (13.9\%). In this result, the Strongyle species were highly prevalent than other parasite genera. This result lower when compare with Adame [22] who reported strongyles (23.4\%), Coccidia (2.6\%), Paramphistomum (33.3\%) prevalence in dairy cow in cheffa dairy farm. The prevalence difference among the genera of helminth in different study area indicates that the topography and climatic condition of each study area vary from one another in supporting infectivity of different parasite and development of their intermediate hosts.

\section{Conclusion and Recommendations}

The present study conducted on small holder dairy farm on endoparasites from December up to end of April for five months in and around Harar town of Oromia regional state, Eastern Ethiopia. This study showed that an internal parasite in small holder dairy cow is one of the most prevalent diseases in the area affecting the wellbeing of the animals. However, the attention given to disease so far was not satisfactory in that there were perhaps little or no attempts made to study the epidemiology of the disease. Hence, to get clear epidemiological picture of the disease, comprehensive study should be launched in the area where small holder dairy cows are abundant and practically participating in agricultural practices and play significant role in this sector.

Even though, small holder dairy farms are paramount important animals in the farming system of the country, the existing livestock extension package programmed of region, saying little out the management and health aspects of small holder daily cows. Based on the aforementioned conclusion, the following recommendations are indicated: significance of these parasites should not be underestimated as they reduce the growth, productivity, reproductive potential of animals; Strategic treatment with appropriate, effective and broad spectrum anathematic should be practiced at the beginning and after the end of rainy seasons. Such treatment regime is targeted to get ridoff the parasites burden of the host animals and minimize pasture contamination by dropping faecal output; the government should formulate an appropriate policy regarding small holder dairy cow's management and health aspects and this should be hold in the livestock extension package programmed; the field veterinarians and stock owners should be aware of the importance and burden of the parasitic disease in small holder dairy farm; this study did not consider the breeds of animals, management and feeding systems, seasonal helminth dynamics, and identification of parasite to species level. Therefore, future detailed works should be undertaken.

\section{Competing Interest}

The authors declare that they have no competing interest.

\section{Acknowledgements}

Authors would like to thank the faculty of veterinary medicine of Haramaya University support of this work and dairy farm owners for their cooperation.

\section{References}

1. World Bank (2001) Livestock Development Report, World Bank, Washington DC, USA.

2. Felleke G, Woldearegay M, Haile G (2009) SNV Ethiopia. Dairy Policy Inventory of Ethiopia, pp: 5-14

3. Johannes C, Johan H, Georg VSM, Pierre D, Jozef V (2009) Gastrointestinal nematode infections in adult dairy cattle: Impact on production, diagnosis and control. Veterinary Parasitology 164: 70-79.

4. McLeod RS (1995) Costs of major parasites to the Australian livestock industries. International Journal for Parasitology 25: 1363-1367.

5. Alekaw L (2000) Distribution of ticks and tick born diseases at Metekel branch, Ethiopia. J Ethiop Vet Assoc 4: 40-60.

6. Newman RL (1995) Recommendation to Minimize Selection for Anthehelminthic Resistance in Nematode Control Program. CSIRO Division of Animal Health, pp: 161-169.

7. Murray M, Rushton B (1997) The Pathology of Fascilosis and the Effect of Large Doses of GIT Nematodes on the Histology and Biochemistry of the Smal Intestine of Lambs. Int J Parasitol 3: 349-361.

8. Hansen J, Perry B (1994) The Epidemiology, Diagnosis and Control of Helminth Parasites of Ruminants. A handbook. ILRAD, Nairobi, Kenya.

9. Onah DN, Nawa Y (2000) Mucosal Immunity Against Parasitic Gastrointestinal Nematodes. Korean J Parasitol 38: 209-236.

10. Soulsby ESW (1982) Helminths, Arthropods and Protozoa of Domesticated Animals. 7th edn. Bailliere Tindall, London; lea and Febiger, Philadelphia, pp: 212-258.

11. Urquhart GM, Armour J, Duncan JL, Dunn AM, Jennings FW (1996) Veterinary Parasitology. 2nd edn. Blackwell Science, United Kingdom, p: 307.

12. Kaplan RM (2006) Update on parasite control in small ruminants 2006: addressing the challenges posed by multiple-drug resistant worms. Proc Am Assoc Bovine Pract, Saint Paul, Minnesota 39: 1-16.

13. Tibbo M, Aragaw K, Philipsson J, Malmfors B, Nasholm A, et al. (2005) Economics of sub-clinical helminthosis control through anthelmintics and supplementation in Menz and Awassi-Menz crossbred sheep in Ethiopia. 56th Annual Meeting of the EAAP, pp: 5-8.

14. Ploeger HW, Kloosterman DC, Borge Steede FH, Eysken M (1990) Effect of Natural occurring Nemotod infection in the $1^{\text {st }}$ and $2^{\text {nd }}$ grazing season on the growth of second year grazing cattle. Veterinary Parasitology 36: 57-70.

15. Harar Agricultural Office (1999) Harar agricultural office annual report of the 1998/1999 fiscal year.

16. Urquhart GMJ, Armour JL, Duncan AM, Dunn FW, Jennings J (1987) Department of Veterinary Parasitology. 2nd edn. Blackwell science, United Kingdom, p: 22. 
Citation: Keno L, Abera B, Lemma D, Eticha E, Assefa G (2017) Study on the Prevalence of Endoparasites in Small Holder Dairy Farm in and around Harar Town, Oromia Regional State, Eastern Ethiopia. J Vet Sci Technol 8: 411. doi: 10.4172/2157-7579.1000411

17. Assegid W (2000) Constraints to live stock and its products in Ethiopia: Policy implications. DVM Thesis, Faculty of Veterinary Medicine, Addis Ababa University, Debre-Zeit, Ethiopia, p: 52.

18. Lemma B, Gabre-Ab F, Tedla S (1985) Studies on fascioliasis in four selected sites in Ethiopia. Veterinary parasitology 18: 29-37.

19. Derib Y (2005) The Study on Endoparasite of Dairy Cattle in Bahir-Dar and its Surrounding. DVM Thesis, FVM, AAU, Debre Zeit, Ethiopia
20. Etsehiwot W (2004) Study on bovine gastrointestinal helminthes in dairy cows in around Holetta. DVM Thesis, Debre Zeit, Ethiopia.

21. Zerfu M (1991) The Study on the Prevalence of Gastro-Intestinal Helminthes of Cattle in Chilalo Awraja Arsi Administrative Region. DVM Thesis, Debre Zeit, Ethiopia.

22. Adame $Z$ (1985) Importance of helmintaisis in the cheffa dairy farm. DVM Thesis, FVM, AAU, Ethiopia, p: 2 